\title{
INDICAÇÕES BIBLIOGRÁFICAS
}

\section{Determinantes e antecedentes do bem-estar e da felicidade}

\author{
Luciana Massaro Onusic | lucianaonusic@gmail.com
}

É crescente, especialmente nas economias mais desenvolvidas, a visão de que a prosperidade dos países não deve ser aquilatada por métricas de natureza exclusivamente econômica. Assim, sob recomendações de organismos internacionais, nos últimos anos, o tema da felicidade tem despertado a atenção dos governos ao redor do mundo, tendo sido considerado na composição de indicadores de desempenho de gestão de políticas públicas. Adicionalmente, o meio corporativo também tem identificado oportunidades ao tratar desse tópico. Em decorrência da natureza complexa dessa temática, a agenda de pesquisa acerca dos determinantes do bem-estar e da felicidade caracterizase por um caráter conexo, integrando diferentes áreas do conhecimento, como psicologia, neurociência, economia, sociologia e medicina. As obras indicadas pela professora Luciana Massaro Onusic da Escola Paulista de Política, Economia e Negócios (EPPEN/UNIFESP) são fundamentais para o aprofundamento do tema.

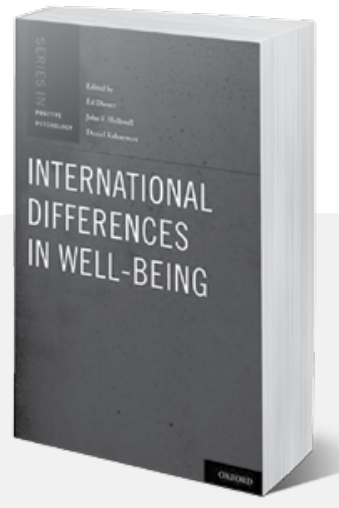

INTERNATIONAL DIFFERENCES IN WELL-BEING

Ed Diener. John F. Helliwell e Daniel Kahneman. Oxford: Oxford University, 2010. 489 p.

Este livro, estruturado em três seções, reúne o trabalho de estudiosos que são referência no tema mensuração e compreensão do bem-estar subjetivo, em diferentes países e culturas. Suas contribuições estão na fronteira da economia e também da ciência social em geral, indicando que a explicação das diferenças internacionais da felicidade vai além de circunstâncias materiais. Esta obra constitui referência por extrapolar abordagens simplistas dos aspectos determinantes do bem-estar.

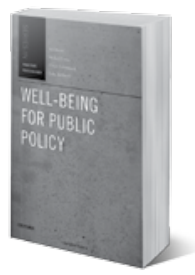

\section{WELL-BEING FOR PUBLIC POLICY}

Ed Diener. Richard Lucas, Ulrich Schimmack e John Helljwell. Oxford: Oxford University, 2009. 256 p.

Os autores desta obra buscam apresentar uma compreensão contemporânea da complexa relação entre política de bem-estar e políticas públicas, assunto interessante para pesquisadores que atuam em áreas como economia e psicologia. 0 livro está organizado em quatro seções, as quais abordam essencialmente a mensuração do bem-estar e seu emprego no âmbito de políticas públicas. Além disso, os autores tratam de limitações da economia e indicadores sociais.

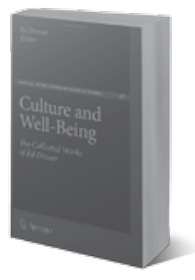

\section{CULTURE AND WELL-BEING}

Edward Diener (Org.). New York: Springer, 2009. 289 p.

Há várias décadas, o professor Diener, organizador desta obra, tem contribuído para rigorosas pesquisas acerca do bem-estar subjetivo. Este livro constitui particular referência por tratar-se de uma coletânea de manuscritos pioneiros ao redor do tema do bem-estar humano. Portanto, interessa a todos os pesquisadores que estão trabalhando para promover a prosperidade das pessoas. Ao longo desta obra, é contextualizada e discutida a relação entre cultura e bem-estar subjetivo.

\section{FINANCE AND THE GOOD SOCIETY}

Robert J. Shiller. Princeton: Princeton University, 2012. 288 p.

Robert Shiller, um dos professores de finanças mais prestigiados da atualidade, discute aqui o papel de finanças na sociedade moderna. A obra apresenta uma perspectiva desafiadora, discutindo o reconhecimento da área financeira como uma poderosa ferramenta para soluções de problemas comuns, aumentando o bem-estar geral da sociedade. Em síntese, defende-se a ideia de que o bem-estar das pessoas é dependente do grau de inovação dos produtos financeiros.

\section{WELL-BEING: Foundations of hedonic psychology \\ Daniel Kahneman. Edward Diener e Norbert Scwarz. New York: Russell Sage Foundation, 2003. 593 p.}

Este livro constitui referência aos interessados no estudo do bem-estar. Oferece 0 início de uma nova integração de estudos sociais e biológicos que ajudam a explicar o que torna a vida agradável ou não. Nos cinco capítulos desta obra, os autores apresentam uma síntese sobre conceitos de bem-estar, personalidade e diferenças individuais, contexto social, abordagem cognitiva, econômica e perspectivas neurocientíficas, estabelecendo bases para uma nova psicologia hedônica. 